ASTHMA

\title{
Airway inflammation in children with difficult asthma: relationships with airflow limitation and persistent symptoms
}

\author{
D N R Payne, Y Qiu, J Zhu, L Peachey, M Scallan, A Bush, P K Jeffery
}

Thorax 2004;59:862-869. doi: 10.1136/thx.2003.017244

\begin{abstract}
See end of article for authors' affiliations

Correspondence to:

Professor P K Jeffery, Lung

Pathology, Royal

Brompton Hospital,

Sydney Street, London

SW3 6NP, UK; p.jeffery@

imperial.ac.uk
\end{abstract}

Received 10 October 2003

Accepted 24 June 2004

\begin{abstract}
Background: The effective management and development of new treatments for children with difficult asthma requires investigation of the underlying airway pathology and its relationships with persistent symptoms and airflow limitation.

Methods: The density of immunologically distinct inflammatory cells and cells expressing interleukin (IL)-4, IL-5, and RANTES was determined in paraffin-embedded endobronchial biopsy specimens from 27 children with difficult asthma (6-16 years) following treatment with systemic corticosteroids. Eleven nonasthmatic children (7-16 years) acted as controls. Reticular basement membrane (RBM) thickness was also recorded and forced expiratory volume in 1 second $\left(\mathrm{FEV}_{1}\right)$ and exhaled nitric oxide $\left(\mathrm{FE}_{\mathrm{NO}}\right)$ measured, the latter in asthmatic children only.

Results: RBM thickness was greater in the asthmatic than the control group (median (range) 7.4 (3.1-11.1) $v 5.1(3.5-7.5) \mu \mathrm{m}, \mathrm{p}=0.02)$. No other significant tissue difference was seen, nor was there a difference between asthmatic subjects with daily symptoms after systemic corticosteroids and those who became asymptomatic. CD4+ T lymphocyte density was higher in asthmatic subjects with persistent airflow limitation (post-bronchodilator $\mathrm{FEV}_{1}<80 \%$ predicted) than in those without $(9.1$ (5.5-13.6) v 3.5 (0.6$34.9) \%, p=0.027)$. Analysing all asthmatic subjects together, there were negative correlations between $\mathrm{CD} 4+\mathrm{T}$ lymphocytes and both pre-bronchodilator $\mathrm{FEV}_{1}(r=-0.57(95 \% \mathrm{Cl}-0.79$ to -0.23$), \mathrm{p}=0.002)$ and post-bronchodilator $\mathrm{FEV}_{1}(r=-0.61$ (95\% Cl -0.81 to -0.29$\left.), \mathrm{p}<0.001\right)$. There were no significant correlations between $\mathrm{FE}_{\mathrm{NO}}$ and inflammatory cells of any type.

Conclusion: In children with difficult asthma treated with systemic corticosteroids, persistent airflow limitation is associated with a greater density of CD4+ T lymphocytes in endobronchial biopsy specimens.
\end{abstract}

C hildren with difficult asthma experience continuing symptoms despite maximal conventional treatment. ${ }^{1}$ Their lives are severely disrupted with frequent hospital visits, school absence, and limitation of normal activities. Persistent airflow limitation is present in a proportion of these patients. ${ }^{2}$ Although they probably account for less than $5 \%$ of all children with asthma, their contribution to morbidity and use of health service resources is disproportionately large.

The management of this group of children is complex, with little evidence to guide the choice of further treatment for those who remain symptomatic even after the use of regular systemic corticosteroids. A number of other treatments have been tried, including cyclosporin, methotrexate, and intravenous immunoglobulin. ${ }^{1}$ However, there is no guarantee of success with any of these, and all have the potential to cause serious adverse effects. The development of effective treatment for children with difficult asthma requires investigation of the underlying immunopathology in order to understand better the relationships with lung function and symptoms, to optimise the use of current treatments, and to identify potential targets for new treatments.

A case series of six children with oral corticosteroid dependent asthma reported thickening of the reticular basement membrane (RBM) and minimal cellular inflammation in endobronchial biopsy specimens, with normal lung function in the majority of cases. ${ }^{3}$ de Blic and colleagues examined the airway pathology in a group of asthmatic children with persistent airflow limitation (forced expiratory volume in 1 second $\left(\mathrm{FEV}_{1}\right)<80 \%$ predicted) despite high dose inhaled corticosteroids and long acting $\beta_{2}$ agonist. ${ }^{4}$ Greater numbers of intraepithelial eosinophils and neutrophils were seen in endobronchial biopsy specimens from the subgroup with persistent symptoms than in those with few symptoms. No differences were reported between the subgroups with respect to subepithelial inflammatory cells. ${ }^{4}$ Our group has also reported the absence of a relationship between subepithelial eosinophilia and symptoms in a group of children with difficult asthma following treatment with oral prednisolone. ${ }^{5}$ RBM thickening is a consistent finding in all studies of difficult asthma in children. ${ }^{346}$ Levels of interleukin (IL)-4, IL-5, and interferon- $\gamma$ have been reported in bronchoalveolar lavage fluid, ${ }^{4}$ but there are no quantitative data regarding cytokine expression in endobronchial biopsy specimens. There are few data concerning the possible relationships between inflammatory cells and lung function in this group.

The paucity of published data reflects the challenging nature of this area of research. Invasive procedures such as endobronchial biopsy cannot be performed in children for research purposes alone. ${ }^{7}$ Opportunities must therefore be taken to obtain samples for research at a time of a clinically indicated procedure. Unlike studies involving adults, ethical constraints also limit the capacity to perform intervention studies using biopsy performed before and after treatment, and make it difficult to obtain data from healthy controls. ${ }^{8}$ Non-invasive markers of airway inflammation such as exhaled nitric oxide $\left(\mathrm{FE}_{\mathrm{NO}}\right)^{9}$ are much more suitable for longitudinal and intervention studies, thus emphasising the need to maximise the opportunities to compare invasive and non-invasive techniques.

Abbreviations: $\mathrm{FE}_{\mathrm{NO}}$, exhaled nitric oxide; $\mathrm{FEV}_{1}$, forced expiratory volume in 1 second; PAL, persistent airflow limitation; RBM, reticular basement membrane 
The aim of this study was therefore to describe the nature of the inflammatory cell infiltrate in endobronchial biopsy specimens from children with difficult asthma, following treatment with systemic corticosteroids, in order to obtain preliminary data to inform future studies and generate hypotheses. We analysed endobronchial biopsies from children with difficult asthma and a "control" group of non-asthmatic children being investigated for respiratory problems other than asthma. Our specific objectives included: (1) measurement of the relative cell densities of subepithelial eosinophils, neutrophils, CD4+ and CD8+ T cells and cells expressing mRNA for IL-4, IL-5 and "regulated on activation, normal T cells expressed and secreted" (RANTES), as well as measurement of RBM thickness; (2) comparison of these parameters between the asthmatic and "control" groups; (3) within the group of asthmatic subjects overall, comparison between those with daily symptoms and those with few symptoms, and between those with and without persistent airflow limitation following systemic corticosteroids; (4) determination of the associations between $\mathrm{FE}_{\mathrm{NO}}$ and inflammatory cells and IL-4, IL-5, and RANTES gene expression.

\section{METHODS}

\section{Subjects}

Thirty six children with difficult asthma were studied (table 1). Asthma was diagnosed according to American Thoracic Society criteria. ${ }^{10}$ Difficult asthma was defined as "symptoms requiring rescue bronchodilator on at least 3 days/week, despite treatment with $\geqslant 1600 \mu \mathrm{g} /$ day inhaled budesonide or equivalent, and regular long acting $\beta_{2}$ agonist (or a previous unsuccessful trial of long acting $\beta_{2}$ agonist) and/or regular prednisolone". ${ }^{5}$ Subjects underwent bronchoscopy and endobronchial biopsy as part of their clinical assessment. ${ }^{11}$ Thirty two patients received additional treatment with systemic corticosteroids (2 weeks oral prednisolone $40 \mathrm{mg} /$ day $(\mathrm{n}=30)$ or oral dexamethasone $6 \mathrm{mg} /$ day $(\mathrm{n}=1)$, or a single intramuscular injection of triamcinolone $80 \mathrm{mg}(\mathrm{n}=1))$ before bronchoscopy. Four patients already on high dose maintenance systemic corticosteroids (prednisolone $40 \mathrm{mg} /$ day $(\mathrm{n}=2)$, intramuscular triamcinolone $80 \mathrm{mg}$ monthly $(\mathrm{n}=2)$ ) underwent bronchoscopy with no further increase in treatment. Before bronchoscopy all patients recorded the number of symptom free days for 2 weeks and then performed spirometric tests ${ }^{12}$ followed by measurement of $\mathrm{FE}_{\mathrm{NO}}$, as previously described. ${ }^{13}$ Serum prednisolone and cortisol levels were measured in those prescribed prednisolone. Adherence was considered satisfactory if there was detectable prednisolone, with cortisol levels $<100 \mathrm{nM}^{13}$

Endobronchial biopsy was performed in 11 non-asthmatic children undergoing bronchoscopy for other clinical indications (table 2). Details of 16 asthmatic children and nine controls have previously been reported. ${ }^{56}$ Reference data for $\mathrm{FE}_{\mathrm{NO}}$ (reported previously) were obtained from 55 nonasthmatic children. ${ }^{13}$

The hospital ethics committee approved the study and the parents of the subjects gave written informed consent.

\section{Clinical definitions}

- Daily symptoms: use of rescue bronchodilator on each of the last 7 days before bronchoscopy.

- Asymptomatic: use of rescue bronchodilator on $\leqslant 1$ out of the last 7 days before bronchoscopy.

- Persistent airflow limitation: post-bronchodilator $\mathrm{FEV}_{1}$ $<80 \%$ predicted (in the presence of an $\mathrm{FEV}_{\mathrm{I}} / \mathrm{FVC}$ ratio of $<0.8$ ) following high dose systemic corticosteroids ( 14 days of oral prednisolone ( $40 \mathrm{mg} /$ day) or
Table 1 Clinical characteristics of children with difficult asthma $(n=36)$

\begin{tabular}{|c|c|}
\hline Male/female & $23 / 13$ \\
\hline Age (years) & $13(6-16)$ \\
\hline $\mathrm{FEV}_{1}$ (\% predicted) & $77(37-103)$ \\
\hline Post-bronchodilator $\mathrm{FEV}_{1}$ (\% predicted) & $85(47-110)$ \\
\hline Atopic & $34^{*}$ \\
\hline Family history of atopy & 31 \\
\hline Parental smoking & $14 \dagger$ \\
\hline Age of first symptoms (years) & $1(1-11)$ \\
\hline Admissions in the previous 12 months & $1.5(0-10)$ \\
\hline Ever intubated & 5 \\
\hline \multicolumn{2}{|l|}{ Treatment: } \\
\hline Budesonide (mg/day) $(n=13)$ & $2.0(0.8-4.0) \ddagger$ \\
\hline Fluticasone (mg/day) $(\mathrm{n}=23)$ & $1.0(1.0-4.0)$ \\
\hline Long acting $\beta_{2}$ agonist & 33 \\
\hline Regular systemic steroids & $12 \S$ \\
\hline \multicolumn{2}{|l|}{ Other treatments (current or previous use) } \\
\hline Montelukast & 23 \\
\hline Theophylline & 10 \\
\hline Antihistamines & 16 \\
\hline Cyclosporin & 1 \\
\hline Intravenous immunoglobulin & 2 \\
\hline Subcutaneous terbutaline & 2 \\
\hline Methotrexate & 1 \\
\hline \multicolumn{2}{|c|}{$\begin{array}{l}\text { Data are presented as median (range) or as absolute numbers (out of } \\
\text { 36). } \\
\text { *Defined as one or more positive radioallergosorbent tests (RASTs). } \\
\text { †Smoking based on reported history. No objective measurements such as } \\
\text { urinary cotinine were performed. } \\
\text { †lncludes one patient prescribed both budesonide } 800 \mu \mathrm{g} / \text { day and ora } \\
\text { prednisolone } 5 \mathrm{mg} / \text { day. } \\
\text { §Oral prednisolone }(\mathrm{n}=10) \text {; intramuscular triamcinolone }(\mathrm{n}=2) \text {. }\end{array}$} \\
\hline
\end{tabular}

dexamethasone (6 mg/day) or a single dose of intramuscular triamcinolone $(80 \mathrm{mg})) .{ }^{14}$

\section{Bronchoscopy and biopsy}

Bronchoscopy was performed under general aneasthesia as previously described. ${ }^{11}$ Biopsy specimens were taken from the right lower lobe subcarinae, fixed in $4 \%$ paraformaldehyde, and embedded in paraffin wax. Sections $(5 \mu \mathrm{m})$ were stained with haematoxylin and eosin to assess morphology. Suitable biopsies were selected for performance of immunostaining and in situ hybridisation (ISH) procedures on further sections. Neutrophils and eosinophils were identified using the EnVision-alkaline phosphatase (EV-AP) technique (K4017, DAKO Ltd, Cambridge, UK), and CD4+ and CD8+ $\mathrm{T}$ cells were identified using the EnVision peroxidase staining method (DAKO Ltd), as previously described. ${ }^{15}$ Monoclonal antibodies were applied which had been raised from mouse against human intracellular epitopes neutrophil elastase (NE) (DAKO, Ely, UK M0725) for neutrophils, human eosinophilic cationic protein and eosinophil protein $\mathrm{X}$ (EG2) (Pharmacia \& Upjohn Diagnostics AB, Uppsala, Sweden) for eosinophils, and against membrane associated epitopes CD4+/CD45RO+ (OPD4) (DAKO, Ely, UK M0834) for CD4+ T cells and CD8 (DAKO, Ely, UK M7103) for CD8+ T cells. The preparation of cRNA probes for IL-4, IL-5 and RANTES and the technique of non-isotopic ISH were performed as described previously. ${ }^{16}$

\section{Quantification}

Sections were coded and counted in random order by a single observer who was unaware of their origin. Immunostaining and ISH were assessed by the validated stereological technique of point counting ${ }^{17}$ using light microscopy (at $\times 400$ magnification) fitted with an eyepiece graticule containing 100 equidistant points (Pyser-SGI, Kent, UK). All evaluable areas of submucosa below the RBM were analysed. For CD4, CD8, IL-4, IL-5 and RANTES, points 
Table 2 Clinical characteristics of the non-asthmatic control group $(n=11)$

\begin{tabular}{|c|c|c|c|c|c|}
\hline Age (years) & $M / F$ & FEV $_{1}(\%)$ & Indication & Previous treatment & Outcome \\
\hline 9 & M & 72 & Haemoptysis & Antibiotics & $\begin{array}{l}\text { No bleeding point found; Staph aureus in } \\
\text { BAL fluid }\end{array}$ \\
\hline 12 & $\mathrm{~F}$ & 105 & Haemoptysis & None & No cause found; symptoms resolved \\
\hline 10 & $\mathrm{~F}$ & 69 & Suspected tracheomalacia* & Bronchodilators, inhaled steroids & Diagnosis confirmed \\
\hline 8 & M & 104 & Chronic cough* & $\begin{array}{l}\text { Antibiotics, bronchodilators, } \\
\text { inhaled steroids }\end{array}$ & No cause found; symptoms resolved \\
\hline 10 & $\mathrm{~F}$ & 86 & Haemoptysis & None & No cause found; symptoms resolved \\
\hline 10 & $\mathrm{~F}$ & 78 & $\begin{array}{l}\text { Recurrent lower respiratory } \\
\text { tract infections* }\end{array}$ & $\begin{array}{l}\text { Antibiotics, bronchodilators, } \\
\text { inhaled steroids }\end{array}$ & No cause found \\
\hline 7 & $\mathrm{~F}$ & $\dagger$ & $\begin{array}{l}\text { Persistent left upper lobe } \\
\text { collapse; cause unknown* }\end{array}$ & $\begin{array}{l}\text { Antibiotics, bronchodilators, } \\
\text { inhaled steroids }\end{array}$ & Subsequent left upper lobectomy \\
\hline 16 & $\mathrm{~F}$ & 108 & Chronic cough & Antibiotics & Subsequent diagnosis of GOR \\
\hline 11 & $\mathrm{~F}$ & 81 & Chronic cough & Antibiotics & Tracheobronchomalacia diagnosed \\
\hline 15 & $\mathrm{~F}$ & 85 & Suspected tracheomalacia & None & Diagnosis confirmed \\
\hline 10 & M & 76 & Recurrent productive cough & Antibiotics & $\begin{array}{l}\text { Staph aureus and Haemophilus influenzae on } \\
\text { BAL. Treated with antibiotics and omeprazole }\end{array}$ \\
\hline
\end{tabular}

BAL, bronchoalveolar lavage; GOR, gastro-oesophageal reflux.

*Prescribed inhaled corticosteroids in the month before bronchoscopy.

†Unable to perform spirometric tests.

overlying positively staining cells were counted as positive and those overlying other areas of submucosa counted as negative. For both EG2 and NE, points overlying any area of positive staining, whether intracellular or extracellular (that is, stored secretory or secreted protein), were counted as positive. ${ }^{5}$ Points overlying muscle, blood vessels, gland and undefinable spaces were excluded. For all cell types, one section from each biopsy was counted for each subject. Sections were considered suitable if the different components of epithelium, RBM, and subepithelium could be easily distinguished. A minimum of 200 points (equivalent to two high power fields) per subject was counted for the data to be included in the final statistical analysis. ${ }^{17}$ For each individual, the volume density for the parameter of interest was calculated as the sum of all positive points in the sections analysed for that subject, divided by the total number of points counted and multiplied by 100 to express the result as a percentage. ${ }^{17}$ RBM thickness was measured on haematoxylin and eosin stained sections, as described previously. ${ }^{6}$

\section{Repeatability and variability}

Intraobserver repeatability for each parameter was assessed by counting the same section four times on four different days, expressed as the \% coefficient of variation (CV). Within-biopsy variability was assessed by examining three sections, at least $25 \mu \mathrm{m}$ apart, from the same biopsy,
(A) Eosinophils (EG2)

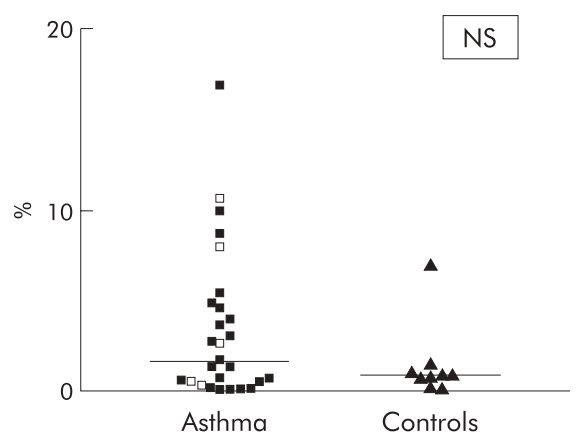

(C) $\mathrm{CD} 4+\mathrm{T}$ lymphocytes

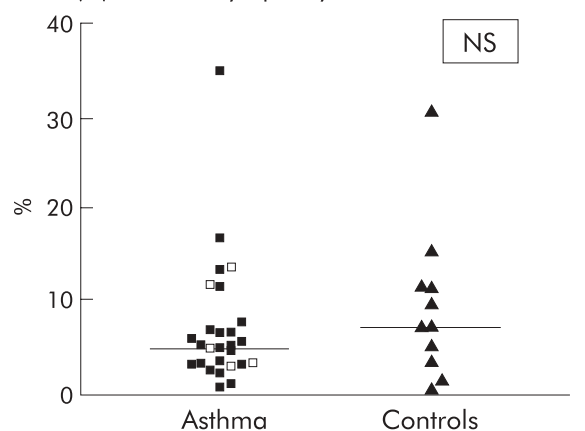

(B) Neutrophils (NE)

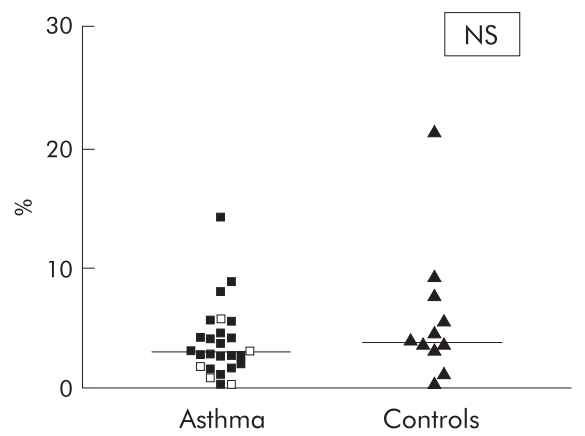

(D) CD8+ T lymphocytes

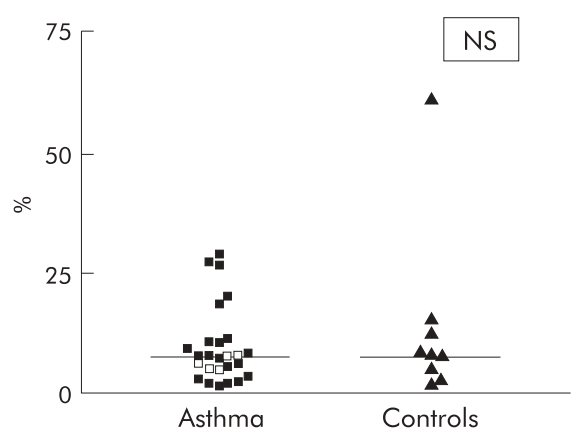

Figure 1 Inflammatory cell density (\%) in asthmatic and control groups. Closed symbols indicate satisfactory adherence, open symbols indicate adherence unknown. 
expressed as the \% CV. Between-biopsy variability was assessed by examining a single section from at least four different biopsies, expressed as the \% CV.

\section{Statistical analysis}

The distribution of the data was examined and nonparametric tests applied as appropriate. Comparison between two groups was made using Mann-Whitney testing. Comparisons between more than two groups were made using the Kruskal-Wallis test, followed by Mann-Whitney testing if a significant difference was found. Bonferroni correction was used for multiple comparisons. Proportions were compared using the $\chi^{2}$ test with Yates' correction. ${ }^{18}$ Spearman rank correlation was used to look for associations. A p value of $<0.05$ was considered statistically significant. Power calculations from an earlier study, based on data approximating to a normal distribution, suggested that a sample size of 11 per group would be needed to detect a mean difference in RBM thickness of $2.25 \mu \mathrm{m}$ at the two sided 5\% significance level with $90 \%$ power. $^{6}$ Sample size calculations based on inflammatory cell data were not possible given the absence of previous data using these techniques in this patient group.

\section{RESULTS}

Bronchoscopy with biopsy was generally well tolerated, with no instances of bronchospasm, pneumothorax or significant bleeding. Significant complications occurred in three asthmatics (desaturation in one requiring administration of muscle relaxant; one child vomited during induction of anaesthesia with no evidence of aspiration and required emergency intubation for the duration of the procedure; and laryngospasm occurred in one child). At least one endobronchial biopsy specimen was obtained from all asthmatic and control subjects. Following processing and quantification of sections, suitable data for analysis of inflammatory cell density were obtained from 27 asthmatics and 11 control subjects with respiratory disease. Not all parameters could be assessed in each subject.

\section{Repeatability and variability}

The \%CV for intraobserver repeatability for the different parameters ranged from $5.4 \%$ to $8.3 \%$. For inflammatory cells, within-biopsy variability ranged from $19 \%$ to $49 \%$ and between-biopsy variability from $38 \%$ to $170 \%$.

\section{Asthmatic subjects $v$ controls}

The data for inflammatory cell density (\%) and RBM thickness in the asthmatic subjects and controls are shown in table 3 and figs $1-3$. The data were not normally distributed. There was no difference between the groups for

(A) IL $-4+$

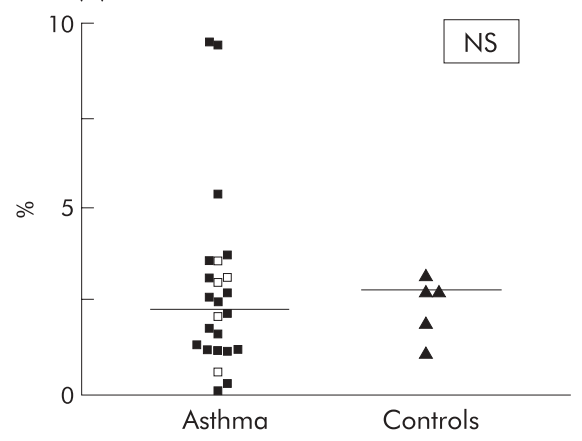

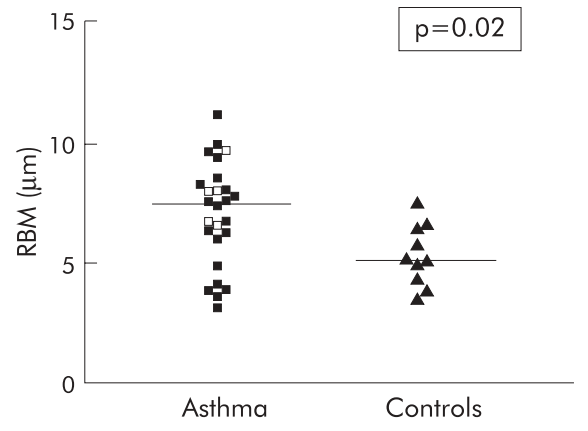

Figure 3 Reticular basement membrane (RBM) thickness $(\mu \mathrm{m})$ in asthmatic and control groups. Closed symbols indicate satisfactory adherence, open symbols indicate adherence unknown.

any of the inflammatory cell types. For ISH, suitable data for analysis of IL-4 and IL-5 was obtained from 24 asthmatics and six controls. There was no difference between groups for the density of either IL-4 or IL-5 mRNA+ cells (fig 2). RANTES expression was assessed in only 12 asthmatics (and no controls) in whom suitable sections were available after completion of all other analyses (table 3). RBM thickness was greater in asthmatics than in controls, supporting a diagnosis of asthma in the group (fig 3). Satisfactory $\mathrm{FE}_{\mathrm{NO}}$ measurements were obtained in 33 asthmatics. $\mathrm{FE}_{\mathrm{NO}}$ was higher in the asthmatic children than the previously published reference range (median (range) $7.4(1.3-30)$ v 5.0 (2.522.7) ppb, $\mathrm{p}<0.01) .{ }^{13}$ The standard deviation of the density of each of the inflammatory cells studied was as follows: eosinophils 4.2, neutrophils 3.0, CD4+ T lymphocytes 6.9, and CD8+ve T lymphocytes 8.0.

Table 3 Endobronchial biopsy data in asthmatic subjects and controls

\begin{tabular}{lll}
\hline & Asthma & Controls \\
\hline Eosinophils (\%) & $1.6(0-16.9)$ & $0.8(0-7.1)$ \\
Neutrophils (\%) & $3.0(0.1-14.1)$ & $4.0(0.5-21.4)$ \\
CD4+ (\%) & $5.2(0.6-34.9)$ & $7.3(0.6-30.6)$ \\
CD8+ (\%) & $7.8(1.4-28.9)$ & $7.6(2.7-61.5)$ \\
IL-4 expression (\%) & $2.3(0.1-9.6)$ & $2.8(1.1-3.2)$ \\
IL-5 expression (\%) & $2.5(0.3-13.1)$ & $3.2(0.7-5.0)$ \\
RANTES expression (\%) & $0.8(0-6.2)$ & Not done \\
RBM $(\mu \mathrm{m})$ & $7.4(3.1-11.1)$ & $5.1(3.5-7.5)^{*}$ \\
\hline
\end{tabular}

IL, interleukin; RBM, reticular basement membrane.

Data are expressed as median (range). All values are expressed as volume density $(\%)$ apart from RBM thickness $(\mu \mathrm{m})$.

${ }^{*} \mathrm{p}=0.02$.

(B) IL $-5+$

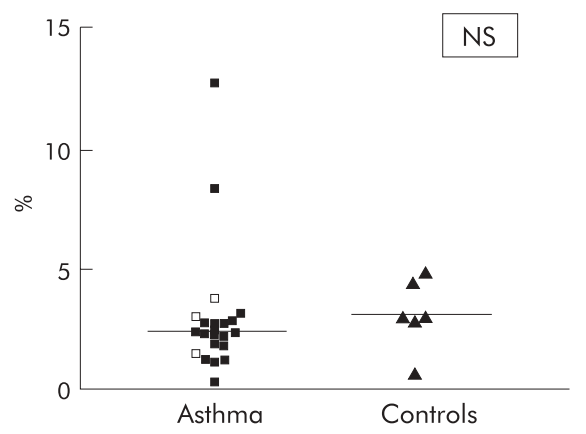

Figure 2 IL-4 and IL-5 positive cells in the asthmatic and control groups. Closed symbols indicate satisfactory adherence, open symbols indicate adherence unknown. 
(A) Eosinophils

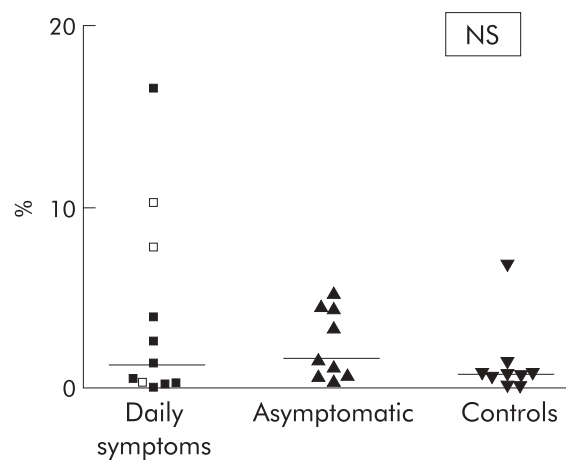

(C) $\mathrm{CD} 4+\mathrm{T}$ lymphocytes

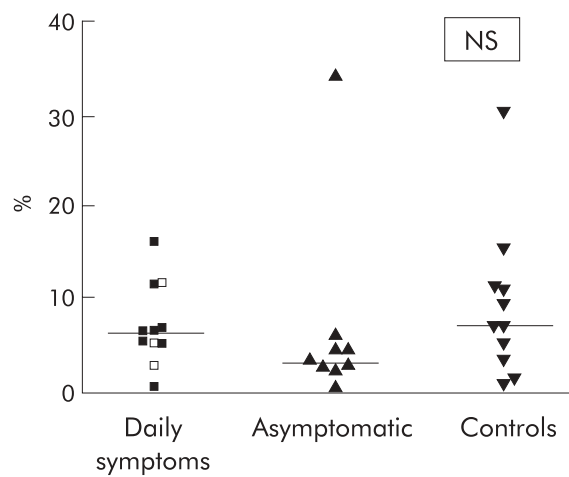

(B) Neutrophils

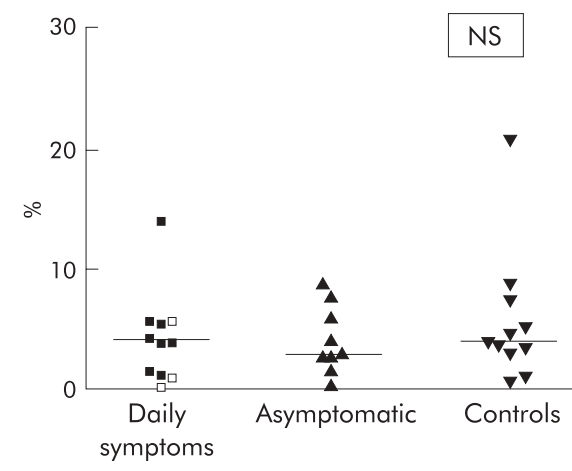

(D) RBM

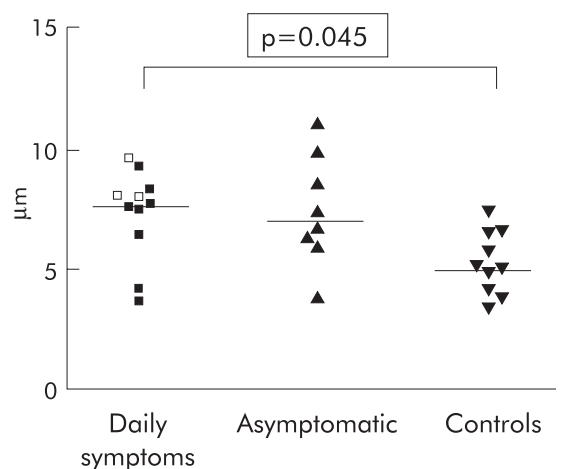

Figure 4 Inflammatory cell density (\%) and RBM thickness $(\mu \mathrm{m})$ in asthmatic subjects with daily symptoms, asymptomatic asthmatics, and controls. Closed symbols indicate satisfactory adherence, open symbols indicate adherence unknown.

\section{Analysis of asthmatic subgroups}

Following systemic corticosteroids, 15 of the 36 patients ( 10 male) had daily symptoms and 11 (6 male) became asymptomatic, as defined above. $\mathrm{FEV}_{1}$ was significantly lower in the subgroup with daily symptoms than in the asymptomatic group, both before (median (range) 67 (37101) $v 89 \quad(75-103) \%$ predicted, $\mathrm{p}=0.008)$ and after bronchodilator $(77(47-106) \vee 95(80-106) \%, \mathrm{p}=0.02)$ The age of onset of respiratory symptoms was also lower in the symptomatic group (median (range) $1(1-5) \vee 3(1-11)$ years, $p=0.03)$. There were no other significant differences in the clinical features between the subgroups. Suitable biopsies for analysis were obtained from 11 subjects with daily symptoms and nine asymptomatic subjects (table 4, fig 4). RBM thickness was significantly greater in the symptomatic group than in controls. No significant differences were seen in inflammatory cells or cytokine expression.
Persistent airflow limitation (PAL) was present in 11 of the 36 patients (PAL+ve) following systemic corticosteroids and bronchodilator, with biopsies suitable for analysis obtained from eight of these. CD4+ T lymphocytes were significantly higher in the PAL+ve asthma subgroup than in the PAL-ve subgroup (median (range) 9.1 (5.5-13.6) v 3.5 (0.6-34.9)\%, $\mathrm{p}=0.027$ ), but were not higher than controls (fig 5). There were no other differences in inflammatory cells between the groups (data not shown). RBM thickness was greater in the PAL - ve asthma subgroup than in controls (7.8 (3.1-11.1) $v$ $5.1(3.5-7.5) \mu \mathrm{m}, \mathrm{p}=0.009)$ but not than the PAL+ve subgroup (5.6 (3.6-9.7) $\mu \mathrm{m}, \mathrm{p}=0.2 \mathrm{l}$; fig 5). Airflow limitation was also analysed as a continuous variable. Significant negative correlations were seen between CD4+ T lymphocytes and both pre-bronchodilator $\mathrm{FEV}_{1}(r=-0.57$ (95\% CI -0.79 to -0.23$), \mathrm{p}=0.002)$ and post-bronchodilator $\mathrm{FEV}_{1}(r=$ $-0.61 \quad(95 \%$ CI -0.81 to -0.29$), p<0.001)$. Significant

Table 4 Endobronchial biopsy data in asthmatic subgroups and controls

\begin{tabular}{|c|c|c|c|}
\hline & $\begin{array}{l}\text { Daily symptoms } \\
(\mathrm{n}=11)\end{array}$ & $\begin{array}{l}\text { Asymptomatic } \\
(n=9)\end{array}$ & $\begin{array}{l}\text { Controls } \\
\text { (n=11) }\end{array}$ \\
\hline Eosinophils (\%) & $1.3(0.01-16.9)$ & $1.6(0.5-5.3)$ & $0.8(0-7.1)$ \\
\hline Neutrophils (\%) & $4.2(0.1-14.1)$ & $2.9(0.1-8.8)$ & $4.0(0.5-21.4)$ \\
\hline $\mathrm{CD} 4+(\%)$ & $6.5(0.6-16.8)$ & $3.5(0.9-34.9)$ & $7.3(0.6-30.6)$ \\
\hline $\mathrm{CD} 8+(\%)$ & $8.9(1.4-26.6)$ & $3.3(1.9-28.9)$ & $7.6(2.7-61.5)$ \\
\hline IL-4 expression (\%) & $2.3(0.1-9.6)$ & $1.9(0.2-9.5)$ & $2.8(1.1-3.2)$ \\
\hline IL-5 expression (\%) & $2.9(0.3-8.6)$ & $2.1(1.2-13.1)$ & $3.2(0.7-5.0)$ \\
\hline $\operatorname{RBM}(\mu \mathrm{m})$ & $7.7(3.6-9.7)^{*}$ & $7.0(3.9-11.1)$ & $5.1(3.5-7.5)$ \\
\hline
\end{tabular}

IL, interleukin; RBM, reticular basement membrane.

Data are expressed as median (range). All values are expressed as volume density (\%) apart from RBM thickness $(\mu \mathrm{m})$.

${ }^{*} \mathrm{p}=0.045 \mathrm{v}$ controls. 
(A) CD4+ve T lymphocytes

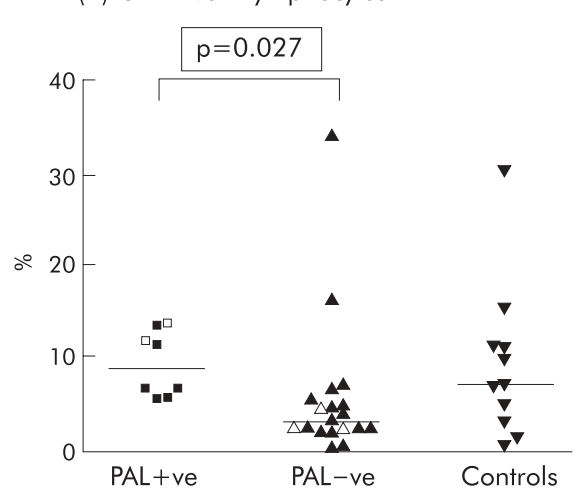

(B) RBM

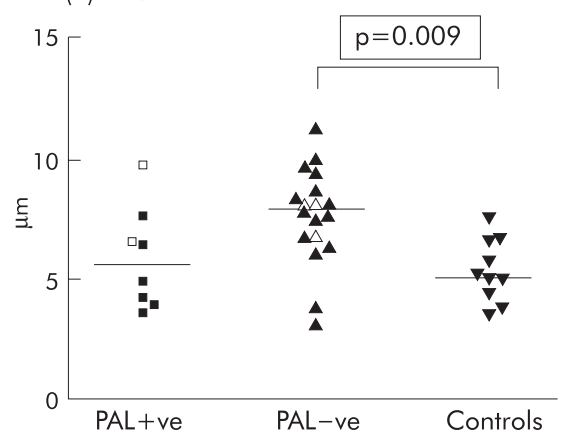

Figure 5 (A) CD4+ve T lymphocytes (\%) and (B) reticular basement membrane (RBM) thickness $(\mu \mathrm{m})$ in asthmatic subjects with (PAL+ve) and without (PAL-ve) persistent airflow limitation and controls. Closed symbols indicate satisfactory adherence, open symbols indicate adherence unknown.

negative correlations were also seen between CD4+ T lymphocytes and the $\mathrm{FEV}_{1} / \mathrm{FVC}$ ratio, both before $(r=$ $-0.5 \quad(95 \%$ CI -0.76 to -0.1$), p=0.015)$ and after bronchodilator $(r=-0.66(-0.87$ to -0.26$), \mathrm{p}=0.003)$. No significant correlations were seen between RBM thickness and either $\mathrm{FEV}_{1}$ or $\mathrm{FEV}_{1} / \mathrm{FVC}$.

Relationship between $\mathrm{FE}_{\mathrm{NO}}$ and endobronchial biopsy For all asthmatics, tests of correlation were applied to explore associations between $\mathrm{FE}_{\mathrm{NO}}$ and inflammatory cells, IL-4, IL-5 and RANTES expression and RBM thickness. No significant correlations were seen, although inspection of the data for $\mathrm{FE}_{\mathrm{NO}}$ and eosinophils suggests that a relationship may exist as one outlying point $\left(\mathrm{FE}_{\mathrm{NO}}=5.4 \mathrm{ppb}\right.$, eosinophil density $=16.9 \%$ ) appeared to skew the results (fig 6). Analysis of the data after exclusion of this value resulted in a significant positive association $(r=0.48$ (95\% CI 0.07 to $0.75), \mathrm{p}=0.02$ ).

\section{DISCUSSION}

This study describes the immunopathology within the airway wall of children with difficult asthma following treatment with systemic corticosteroids. With the exception of RBM thickness, no differences were seen between the asthmatic and control groups. There were also no significant differences in inflammatory cells between asthmatic subjects with daily symptoms and those who became asymptomatic. CD4+ T lymphocyte density was significantly higher in asthmatic subjects with persistent airflow limitation (PAL) than in those without PAL. In the asthmatic group as a whole there were significant negative correlations between CD4+ $\mathrm{T}$

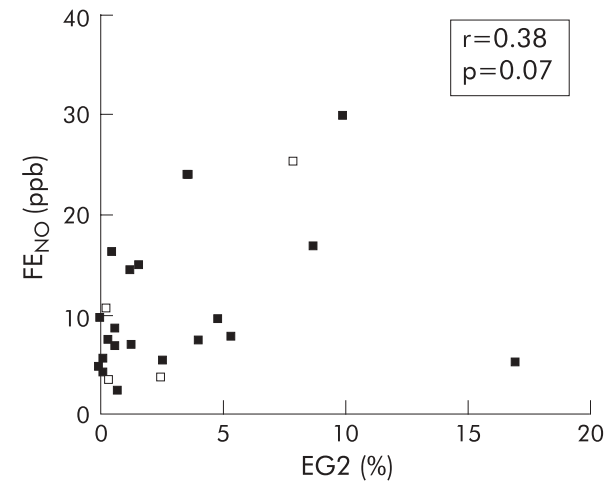

Figure 6 Correlation between exhaled nitric oxide $\left(\mathrm{FE}_{\mathrm{NO}}\right)$ and eosinophils in endobronchial biopsy specimens.

lymphocytes and $\mathrm{FEV}_{1}$ and $\mathrm{FEV}_{1} / \mathrm{FVC}$, both before and after bronchodilator.

This study has extended our previous endobronchial biopsy work investigating the immunopathology of difficult asthma in children, ${ }^{56}$ by providing data regarding immunologically distinct inflammatory cells and gene expression for IL-4, IL-5 and RANTES, and examining their relationships with lung function, symptoms, and $\mathrm{FE}_{\mathrm{NO}}$. We acknowledge that the study has a number of limitations. One of these is the cross sectional, observational design which is similar to all previously published reports of endobronchial biopsy in paediatric asthma..$^{3-6} 81920$ Given the ethical constraints outlined in the introduction, this design is difficult to avoid. However, preliminary studies such as this and others ${ }^{3}{ }^{4}$ are essential to advance this area of research. One of the strengths of these data therefore lies in their potential to generate hypotheses and inform future work. Ideally, subsequent studies would include performance of biopsy before and after an intervention, as is common in adults. Although this was not possible for the present study, it may be possible in the future, given the documented safety of the procedure in a tertiary centre. ${ }^{11}$ However, it would be necessary to establish the benefit to the individual child of performing two bronchoscopies before proceeding with such an approach.

We also acknowledge in the present study the lack of both a healthy control group and a group of patients with mild asthma for comparison. Data from children with mild asthma are difficult although not impossible to obtain, as shown by Barbato and colleagues. ${ }^{8}$ In keeping with the latter study, we obtained reference data from children undergoing bronchoscopy in whom a diagnosis of asthma had been excluded, as discussed previously. ${ }^{6}$ However, it is important to emphasise that all subjects in the control group underwent bronchoscopy for investigation of respiratory symptoms and cannot be considered to be true controls. It is likely that the extent of airway inflammation in the "control" group was greater than would be seen in a genuine healthy control group, even allowing for the fact that some of the controls had been treated with antibiotics and/or inhaled corticosteroids before bronchoscopy. These factors may account, at least in part, for the absence of any differences in inflammatory cells between the asthma and "control" groups. We plan to overcome these limitations in future by performing bronchoscopy and biopsy in children without any history of respiratory disease and those with less severe asthma who are undergoing a general anaesthetic for another elective procedure. Ethical approval for this procedure has been obtained. Krawiec and colleagues have employed a similar approach. ${ }^{21}$

The absence of any significant differences in inflammatory cells between the asthmatic and control groups, and between 
the symptomatic and asymptomatic asthma subgroups, may also reflect a lack of study power, given the relatively small number of subjects. The study was able to detect a difference in RBM thickness, as predicted from our previous data. Other investigators, using data from adult studies, have suggested that a sample size of 15 subjects per group is suitable for studies of inflammatory cells in endobronchial biopsy, with little advantage in increasing the number further. ${ }^{22}$ Our capacity to achieve this sample size for both the control group and the asthmatic subgroups was limited by practical and ethical considerations and by the failure to obtain suitable biopsy specimens for analysis from all the subjects studied.

Endobronchial biopsies were obtained after asthmatic subjects had been treated with high doses of both inhaled and systemic corticosteroids. The decision to perform bronchoscopy after treatment with systemic corticosteroids was taken in order to maximise the safety of the procedure. While this may confound the interpretation of our findings, an advantage of this protocol is that it provides the opportunity to examine the airway pathology in children in whom symptoms and/or abnormalities of lung function persist, even after aggressive corticosteroid treatment. It is especially this group of children for whom guidance on further treatment is needed. In spite of this, we did not find any group differences in the pattern of subepithelial inflammation between subjects with daily symptoms after systemic corticosteroids and those who became asymptomatic. This may reflect a lack of power, as discussed above. However, the results are in agreement with those reported by de Blic and colleagues. ${ }^{4}$ The latter study did demonstrate a difference in inflammatory cells within the epithelium but not the subepithelium. We did not analyse the epithelial layer, in view of the extent of epithelial shedding frequently observed in our biopsy samples.

Although we did not find a relationship between inflammatory cells and symptoms, the data did show an association between CD4+ $\mathrm{T}$ lymphocytes and the degree of airflow limitation, assessed by both $\mathrm{FEV}_{1}$ and the $\mathrm{FEV}_{\mathrm{l}} / \mathrm{FVC}$ ratio. This suggests that failure to achieve normal lung function after treatment with systemic corticosteroids is associated with an impaired ability to suppress T lymphocyte inflammation within the airway. This hypothesis could be tested using an intervention study, with lung function and endobronchial biopsy performed before and after treatment with systemic corticosteroids. In studies of adult asthma, failure of prednisolone to improve lung function has been associated with defects in $\mathrm{T}$ lymphocyte responsiveness to corticosteroids in vitro, ${ }^{24} 25$ and with dysregulation of IL-4, IL-5, and interferon- $\gamma$ gene expression in bronchoalveolar lavage cells. ${ }^{26}$

Other investigators have suggested that persistent airflow limitation in asthma may reflect structural changes in the airway, referred to as remodelling. ${ }^{27}$ Using RBM thickening as a marker of remodelling, this assumption is not supported by the data from the present study, nor by the limited data available from previous biopsy studies of children with severe asthma. ${ }^{36}$

Persistent symptoms and airflow limitation may be due to poor adherence to treatment. We aimed to optimise the assessment of adherence by measuring prednisolone and cortisol levels and prescribing intramuscular triamcinolone, which ensures adherence and bypasses potential problems with drug absorption. Adherence to oral corticosteroids was considered unsatisfactory in five of the asthmatic subjects from whom suitable biopsy specimens were obtained. Given the small number involved, formal analysis of differences between those who were and were not considered adherent is inappropriate. Inspection of the data in fig 1 does not suggest any obvious differences between the two. However, treatment adherence was considered satisfactory in only 12 of the
15 subjects who had daily symptoms compared with all 11 subjects who became asymptomatic. Consequently we have now altered our clinical protocol so that all patients receive intramuscular triamcinolone in order to ensure adherence.

In view of the invasive nature of bronchoscopy, there is a need to develop non-invasive markers of airway inflammation that reflect inflammation measured bronchoscopically. Several studies have found a correlation between $\mathrm{FE}_{\mathrm{NO}}$ and airway eosinophils in induced sputum, bronchoalveolar lavage fluid, and endobronchial biopsy specimens. ${ }^{28-30}$ The data from the present study suggest that a relationship may exist in this group of children with difficult asthma, although the strength of the correlation varies considerably depending on the inclusion or exclusion of an outlying point. The data do not indicate any association between $\mathrm{FE}_{\mathrm{NO}}$ and the other inflammatory cells studied following treatment with systemic corticosteroids. This is in agreement with data from other studies, using both bronchoalveolar lavage and endobronchial biopsy. ${ }^{29} 30$

This study quantifies inflammatory cells and structural alterations in endobronchial biopsy specimens from a group of children with difficult asthma and explores the relationships between inflammatory cells, lung function, and symptoms. The data indicate an association between CD4+ $\mathrm{T}$ lymphocytes and one key aspect of lung function, $\mathrm{FEV}_{1}$, which needs to be explored further. Research into the mechanisms of difficult asthma in children therefore needs to move from observational, hypothesis generating studies such as this and others ${ }^{3-6}$ to interventional studies that are able to test hypotheses and assess the effect of treatment. The design of future studies must be ethically approved and appropriately powered using, initially, data already obtained..$^{3-6}$ It is unlikely that any one centre will be able to recruit sufficient numbers of patients to conduct this type of research. An immediate priority is therefore the establishment of a network of different centres with the expertise to carry out such work.

\section{ACKNOWLEDGEMENTS}

The authors thank Janet Peacock and Indra Narang for statistical advice.

\section{Authors' affiliations}

D N R Payne, A Bush, Department of Paediatrics, Imperial College London at the Royal Brompton Hospital, London SW3 6NP, UK Y Qiu, J Zhu, L Peachey, P K Jeffery, Department of Gene Therapy, Imperial College London at the Royal Brompton Hospital, London SW3 6NP, UK

M Scallan, Department of Anaesthetics, Imperial College London at the Royal Brompton Hospital, London SW3 6NP, UK

This study was funded by Asthma UK.

\section{REFERENCES}

1 Payne DNR, Balfour-Lynn IM. Children with difficult asthma: a practical approach. J Asthma 2001;38:189-203.

2 Chan MT, Leung DY, Szefler SJ, et al. Difficult-to-control asthma: clinical characteristics of steroid-insensitive asthma. J Allergy Clin Immunol 1998; 101:594-601.

3 Jenkins HA, Cool C, Szefler SJ, et al. Histopathology of severe childhood asthma: a case series. Chest 2003;124:32-41.

4 de Blic J, Tillie-Leblond I, Tonnel AB, et al. Difficult asthma in children: an analysis of airway inflammation. J Allergy Clin Immunol 2004;113:94-100.

5 Payne DNR, Adcock IM, Wilson NM, et al. Relationship between exhaled nitric oxide and mucosal eosinophilic inflammation in children with difficult asthma, after treatment with oral prednisolone. Am J Respir Crit Care Med 2001;64:1376-81.

6 Payne DN, Rogers AV, Adelroth E, et al. Early thickening of the reticular basement membrane in children with difficult asthma. Am J Respir Crit Care Med 2003; 167:78-82.

7 Bush A, de Jongste JC, Carlsen $\mathrm{KH}$. Ultrastructural examination of bronchial specimens from children with moderate asthma. Thorax 2003;58:187.

8 Barbato A, Turato G, Baraldo S, et al. Airway inflammation in childhood asthma. Am J Respir Crit Care Med 2003;168:798-803. 
9 Baraldi E, de Jongste JC. Measurement of exhaled nitric oxide in children, 2001. Eur Respir J 2002;20:223-37.

10 American Thoracic Society. Standards for the diagnosis and care of patients with chronic obstructive pulmonary disease (COPD) and asthma. Am Rev Respir Dis 1987; 136:225-44.

11 Payne DNR, McKenzie SA, Stacey S, et al. Safety and ethics of bronchoscopy and endobronchial biopsy in difficult asthma. Arch Dis Child 2001;84:422-5.

12 American Thoracic Society. Standardization of spirometry, 1994 update. Am J Respir Crit Care Med 1995; 152:1107-36.

13 Payne DNR, Wilson NM, James A, et al. Evidence for different subgroups of difficult asthma in children. Thorax 2001;56:345-50.

14 American Thoracic Society. Proceedings of the ATS workshop on refractory asthma: current understanding, recommendations, and unanswered questions. Am J Respir Crit Care Med 2000;162:2341-51.

15 Gamble E, Grootendorst DC, Brightling CE, et al. Anti-inflammatory effects of the phosphodiesterase 4 inhibitor cilomilast (Ariflo) in COPD. Am J Respir Crit Care Med 2003; 168:976-82.

16 Zhu J, Qiu YS, Majumdar S, et al. Exacerbations of bronchitis: bronchial eosinophilia and gene expression for interleukin-4, interleukin-5, and eosinophil chemoattractants. Am J Respir Crit Care Med 2001;164:109-16.

17 Howard CV, Reed MG. Unbiased stereology. In: Three dimensional measurement in microscopy. New York: Springer-Verlag, 1998:55-68.

18 Altman DG. Practical statistics for medical research. London: Chapman and Hall, 1991.

19 Cokugras H, Akcakaya N, Seckin, et al. Ultrastructural examination of bronchial biopsy specimens from children with moderate asthma. Thorax 2001;56:25-9.

20 Mahut B, Delclaux C, Tillie-Leblond I, et al. Both inflammation and remodeling influence nitric oxide output in children with refractory asthma. J Allergy Clin Immunol 2004;113:252-6.
21 Krawiec ME, Westcott JY, Chu HW, et al. Persistent wheezing in very young children is associated with lower respiratory inflammation. Am J Respir Crit Care Med 2001;163:1338-43

22 Richmond I, Booth H, Ward C, et al. Intrasubject variability in airway inflammation in biopsies in mild to moderate stable asthma. Am J Respir Crit Care Med 1996;153:899-903

23 Jeffery PK, Holgate ST, Wenzel SE. Methods for the assessment of endobronchial biopsies in clinical research: application to studies of pathogenesis and the effects of treatment. Am J Respir Crit Care Med 2003;168:1-17.

24 Corrigan CJ, Brown PH, Barnes NC, et al. Glucocorticoid resistance in chronic asthma. Glucocorticoid pharmacokinetics, glucocorticoid receptor characteristics, and inhibition of peripheral blood T cell proliferation by glucocorticoids in vitro. Am Rev Respir Dis 1991;144:1016-25.

25 Syed F, Bingham B, Johnson $M$, et al. The CD4+ T lymphocyte is a site of steroid resistance in asthma. Q J Med 1998;91:567-72.

26 Leung DY, Martin RJ, Szefler SJ, et al. Dysregulation of interleukin 4 interleukin 5, and interferon gamma gene expression in steroid-resistant asthma. J Exp Med 1995;181:33-40.

27 Rasmussen F, Taylor DR, Flannery EM, et al. Risk factors for airway remodeling in asthma manifested by a low postbronchodilator FEV1/vital capacity ratio: a longitudinal population study from childhood to adulthood. Am J Respir Crit Care Med 2002;165:1480-8.

28 Piacentini GL, Bodini A Costella $S$, et al. Exhaled nitric oxide and sputum eosinophil markers of inflammation in asthmatic children. Eur Respir J 1999; 13:1386-90.

29 Warke TJ, Fitch PS, Brown V, et al. Exhaled nitric oxide correlates with airway eosinophils in childhood asthma. Thorax 2002;57:383-7.

30 van den Toorn LM, Overbeek SE, de Jongste JC, et al. Airway inflammation is present during clinical remission of atopic asthma. Am J Respir Crit Care Med $2001 ; 164: 2107-13$.

\section{LUNG ALERT}

Early supported discharge at exacerbation of COPD: safe and cost effective for some

$\Delta$ Ram FSF, Wedzicha JA, Wright J, et al. Hospital at home for patients with acute exacerbations of chronic obstructive pulmonary disease: systematic review of evidence. BMJ 2004;329:315-8.

his systematic review of seven randomised controlled trials $(\mathrm{n}=754$ patients) compared

"hospital at home" with inpatient management of acute exacerbations of COPD.

Carefully selected patients were randomised within 72 hours of presentation to hospital. The combined results show that patients with an acute exacerbation of COPD can be safely and successfully treated at home with support from visiting respiratory nurses and a multidisciplinary team. Readmission and mortality data showed no difference between "hospital at home" and inpatient care (relative risks 0.89 (95\% CI 0.72 to 1.12 ) and 0.61 (95\% CI 0.36 to 1.05 ), respectively). While not an option for all patients (only one in four met the strict inclusion criteria), there were substantial savings in terms of direct financial cost and the number of hospital bed days freed. It also increases patient choice.

It is concluded that, with adequate support and sufficient medication supplies, early discharge of selected patients with exacerbations of COPD is safe and leads to considerable financial savings.

S Cooper

Specialist Registrar, Broomfield Hospital, Essex, UK; samanthacooper@doctors.org.uk 